\title{
Synergistic Effects in Nanoparticle-Based Protective Coatings for Paper and Textiles ${ }^{\dagger}$
}

\author{
Ludmila Otilia Cinteza ${ }^{1, *}$, Adina Raducan ${ }^{1}$, Petruța Oancea ${ }^{1}$, Lia Mara Ditu 1, \\ Cristina Scomoroscenco ${ }^{2}$, Elvira Alexandrescu 2, Cristina Lavinia Nistor ${ }^{2}$, Cristian Petcu ${ }^{2}$, \\ Laura Chirilă ${ }^{3}$ and Ioana Rodica Stănculescu ${ }^{4}$ \\ 1 University of Bucharest, 4-12 Regina Elisabeta Blvd., 030118 Bucharest, Romania; \\ adina.raducan@g.unibuc.ro (A.R.); petrutaoancea73@yahoo.com (P.O.); lia_mara_d@yahoo.com (L.M.D.) \\ 2 National Research and Development Institute for Chemistry and Petrochemistry - ICECHIM, PO 060021 \\ Bucharest, Romania; scomoroscencocristina@gmail.com (C.S.); elviraalxandrescu@yahoo.com (E.A.); \\ lc_nistor@yahoo.com (C.L.N.); cpetcu@icf.ro (C.P.) \\ 3 National Research \& Development Institute for Textiles and Leather, 030508 Bucharest, Romania; \\ chirila_laura@yahoo.com \\ 4 HoriaHulubei - NIPNE, P.O.BOX MG-6, Ilfov -Magurele, 077125 Bucharest, Romania; \\ ioana.stanculescu@nipne.ro \\ * Correspondence: ocinteza@gw-chimie.math.unibuc.ro \\ + Presented at the 15th International Symposium "Priorities of Chemistry for a Sustainable Development" \\ PRIOCHEM, Bucharest, Romania, 30th October-1st November 2019.
}

Published: 15 October 2019

Keywords: multifunctional coatings; superhydrophobic; $\mathrm{ZnO}$ nanoparticles; Ag nanoparticles; chitosan

Superhydrophobic materials have attracted considerable attention during the last decades, since they allow the facile transfer of special wettability properties on various surfaces. Protective coatings that ensure water repellency on asolid surface became the most common way for the treatment of stone or concrete buildings, metal devices, glass, textiles, etc. [1]. Most of these materials are nanohybrids consisting ofa filmogenic matrix with various nanoparticles as fillers, with the main role being to obtain a suitable roughness. In this work, a superhydrophobic coating based on a combination of $\mathrm{ZnO}$ and $\mathrm{Ag}$ nanoparticles embedded in a silica matrix was obtained and synergistic effects in antibacterial and other properties were investigated. Coating materials were prepared with various contents of $\mathrm{ZnO}$ and $\mathrm{Ag}$ nanoparticles embedded in an organo-modified (Ormosil) silica matrix. Ag nanoparticles were synthesized using a "green chemistry" method based on the reduction of silver ions in Thymus vulgaris extract. Zinc oxide nanoparticles were synthesized by using hydrothermal synthesis in high-temperature/high-pressure conditions, in the presence of surfactants as structuring agents. Commercially available normal-type paper and cotton textile were used as the model solid substrate to be functionalized. $\mathrm{Ag}$ and $\mathrm{ZnO}$ nanoparticles were characterized from the point of view of size, surface potential, crystallinity, and shape using dynamic light scattering, XRD, scanning electron microscopy (SEM), and transmission electron microscopy (TEM). The coating materials were prepared by adding various concentrations of $\mathrm{Ag}$ and of $\mathrm{ZnO}$ nanoparticles in a filmogenic silica matrix. The silica nanohybrid was obtained through the sol-gel method, and the deposition of coating material was performed by brushing or spraying onto a solid surface previously functionalized with chitosan. The contact angle of water on modified surfaces of both paper and textile materials wasin the range 150-1600, with sliding angle of less than $7^{\circ}$. A synergistic effect between $\mathrm{ZnO}$ and $\mathrm{Ag}$ nanoparticles was observed in terms of antibacterial activity, but no synergism with the chitosan was proved. Superhydrophobic multifunctional materials were obtained with reduced content of both $\mathrm{Ag}$ and $\mathrm{ZnO}$ nanoparticles. The coatings show 
superior antibacterial activity due to the synergistic effect from the nanoparticulate components, together with UV-protection and self-cleaning properties.

Acknowledgments: This work was supported by grants of the Romanian National Authority for Scientific Research and Innovation, CCCDI-UEFISCDI, project number PN-III-P1-1.2-PCCDI-2017-0743(PC5) and project number PN-III-P1-1.2-PCCDI-2017-0428 (PC2), within PNCDI III.

\section{References}

1. Das, S.; Kumar, S.; Samal, S.K.; Mohanty, S.; Nayak, S.; Anjay, K. A Review on Superhydrophobic Polymer Nanocoatings: Recent Development and Applications. Ind. Eng. Chem. Res. 2018, 57, 2727-2745.

(C) 2019 by the authors. Licensee MDPI, Basel, Switzerland. This article is an open access article distributed under the terms and conditions of the Creative Commons Attribution (CC BY) license (http://creativecommons.org/licenses/by/4.0/). 